\title{
NONLINEAR RETARDED INTEGRAL INEQUALITIES OF GRONWALL-BELLMAN TYPE AND APPLICATIONS
}

\section{A. AbDeldaim}

Abstract. The aim of this paper is to establish some new nonlinear retarded integral inequalities of Gronwall-Bellman type. More accurately we extend certain results which have been proved in El-Owaidy et. al, [12] and Abdeldaim and Yakout [2] to some nonlinear retarded integral inequalities. We also give some applications to estimate the solutions of some nonlinear retarded differential equations to illustrate the effectiveness of some from our results.

Mathematics subject classification (2010): 39B72, 26D10, 34A34.

Keywords and phrases: Integral inequality, retarded integral inequality, retarded integral and differential equations.

\section{REFERENCES}

[1] A. Abdeldaim, A. A. El-Deeb, Some new retarded nonlinear integral inequalities with iterated integrals and their applications in retarded differential equations and integral equations, Journal of Fractional Calculus and Applications. Vol. 5 (3S) No. 9 (2014), pp. 1-9.

[2] A. Abdeldaim, M. Yakout, On some new integral inequalities of Gronwall-Bellman-Pachpatte type, Appl Math Comput. 217 (2011), 7887-7899.

[3] A. Abdeldaim, A. A. El-DeEB, On some new nonlinear retarded integral inequalities with iterated integrals and their applications in integro-differential equations, Br. J. Math. Comput. Sci. 5 (2015), 479-491. Article No. BJMCS.2015.034.

[4] R. P. Agarwal, S. Deng, W. ZHANG, Generalization of a retarded Gronwall-like inequality and its applications, Appl Math Comput. 165 (2005), 599-612.

[5] R. P. Agarwal, Y. H. Kim, S. K. SEN, New retarded integral inequalities with applications, J. Inequal. Appl. (2008), Article ID 908784(2008).

[6] R. Bellman, The stability of solutions of linear differential equations, Duke Math J. 10 (1943), 643-647.

[7] D. Bianove And P. Simeove, Integral Inequalities and Applications, New York, Kluwer Academic Publishers, (1992).

[8] I. A. BIHARI, A generalization of a lemma of Bellman and its application to uniqueness problem of differential equation, Acta Math Acad Sci Hung. 7 (1956), 81-94.

[9] W. S. CHEUnG, Some new nonlinear inequalities and applications to boundary value problems, Nonlinear Anal. 64 (2006), 2112-2128.

[10] H. El-Owaidy, A. Abdeldaim, A. A. El-DeEB, On some new nonlinear retarded integral inequalities with iterated integrals and their applications in differential-integral equations, Mathematical Sciences Letters journal, 3, No. 3 (2014), 157-164.

[11] H. El-Owaidy, A. A. RAGAB, AND A. ABdeldaim, On some integral inequalities of GronwallBellman type, Appl. Math Comut., 106 (1999), 289-303.

[12] H. El-Owaidy, A. A. Ragab, W. Abuelela, A. A. El-Deeb, On some new nonlinear integral inequalities of Gronwall-Bellman type, KYUNGPOOK Math. J. 54 (2014), 555-575.

[13] T. H. GRONWALL, Note on the derivatives with respect to a parameter of the solutions of a system of differential equations, Ann Math. 20 (1919), 292-296.

[14] Y. H. KIM, On some new integral inequalities for functions in one and two variables, Acta Math Sinica. 21 (2005), 423-434. 
[15] O. Lipovan, A retarded Gronwall-like inequality and its applications, J. Math Anal Appl. 252 (2000), 389-401.

[16] B. G. Pachpatte, Inequalities for Differential and Integral Equations, Academic Press London (1998).

[17] B. G. PAChPATte, Explicit bound on certain integral inequalities, J. Math. analysis and Applications, 267 (2002), 48-61.

[18] M. H. M. RASHID, Explicit bound on retarded Gronwall-Bellman inequality, Tamkang J. Math. 43 (2012), 99-108.

[19] W. S. WANG, A generalized retarded Gronwall-like inequality in two variables and applications to BVP, Appl Math Comput. 191 (2007), 144-154.

[20] W. S. WANG, C. SHEN, On a generalized retarded integral inequality with two variables, J. Inequal. Appl. (2008), Article ID 518646 (2008).

[21] W. S. WANG, Z. LI, Y. LI, Y. HUANG, Nonlinear retarded integral inequalities with two variables and applications, J. Inequal. Appl. (2010), Article ID 240790 (2010).

[22] W. S. WANG, R. C. LUO, Z. Li, A new nonlinear retarded integral inequality and its application, J. Inequal. Appl. (2010), Article ID 462163 (2010).

[23] W. S. WANG, Some generalized nonlinear retarded integral inequalities with applications, J. Inequal. Appl. (2012), 2012:31.

[24] W. S. WANG, Some New generalized retarded nonlinear integral inequalities with iterated integrals and thier applications, J. Inequal. Appl. (2012):236.

[25] A. KHAn ZAREen, Integral inequalities of Gronwall-Bellman Type, Applied Mathematics. 5 (2015), 3484-3488. 